\title{
Prevalence of Children's Mental Health Problems and the Effectiveness of Population-Level Family Interventions
}

\author{
Noriko Kato ${ }^{1}$, Toshihiko Yanagawa ${ }^{2}$, Takeo Fujiwara ${ }^{3}$, and Alina Morawska ${ }^{4}$ \\ ${ }^{1}$ Area on Health Promotion Research, National Institute of Public Health, Wako, Saitama, Japan \\ ${ }^{2}$ School of Health and Nursing Science, Wakayama Medical University, Wakayama, Japan \\ ${ }^{3}$ Department of Social Medicine, National Research Institute for Child Health and Development, Tokyo, Japan \\ ${ }^{4}$ Parenting and Family Support Centre, The University of Queensland, Queensland, Australia
}

Received October 28, 2014; accepted June 10, 2015; released online August 5, 2015

Copyright $(\subset 2015$ Noriko Kato et al. This is an open access article distributed under the terms of Creative Commons Attribution License, which permits unrestricted use, distribution, and reproduction in any medium, provided the original author and source are credited.

\begin{abstract}
The prevalence of mental health problems among children and adolescents is of growing importance. Intervening in children's mental health early in life has been shown to be more effective than trying to resolve these problems when children are older. With respect to prevention activities in community settings, the prevalence of problems should be estimated, and the required level of services should be delivered. The prevalence of children's mental health disorders has been reported for many countries. Preventive intervention has emphasized optimizing the environment. Because parents are the primary influence on their children's development, considerable attention has been placed on the development of parent training to strengthen parenting skills. However, a public-health approach is necessary to confirm that the benefits of parent-training interventions lead to an impact at the societal level. This literature review clarifies that the prevalence of mental health problems is measured at the national level in many countries and that population-level parenting interventions can lower the prevalence of mental health problems among children in the community.
\end{abstract}

Key words: child; mental health; prevalence; family intervention; evaluation

\section{INTRODUCTION}

Within the last century, considerable change has been observed in the health and disease patterns of children and young people. ${ }^{1}$ One feature of this "millennial morbidity" is the growing importance of mental health problems. For example, the World Health Organization (WHO) has predicted that internalizing disorders will surpass those of HIV/AIDS in terms of disease burden by the year 2030. ${ }^{3}$ Further, emotional and behavioral problems have become increasingly common among children.

Mental health problems can be a major burden on individuals in everyday situations, such as social relations with friends, family happiness, and school functioning. In addition, mental health problems can be very long-lasting. ${ }^{4}$ If childhood problems are left untreated, only approximately $50 \%$ of preschool children show a natural reduction in behavioral problems. The remaining $50 \%$, however, may experience long-term sequelae, including serious consequences such as a breakdown of family functioning and dropping out of school. Further, alcohol and drug abuse may occur as a result of the development of depression during adolescence and adulthood. This situation imposes a large cumulative drain on society by impairing productivity and incurring social and financial costs associated with suboptimal participation in the labor force and failure to utilize clinical treatment services. ${ }^{5}$

Interventions that occur earlier in one's life have been shown to be preferable to those occurring later in life, in terms of cost and effectiveness. ${ }^{6}$ Therefore, preventive strategies are essential to ensure that problems are dealt with early. Preventive interventions have emphasized optimization of the environment to prevent or manage children's behavior. Because parents are the primary influence on their children's development, considerable attention has been placed on the development of parent training to strengthen parenting skills to prevent the onset of behavioral difficulties. ${ }^{7}$ There is clear evidence linking poor parenting and family risk factors to worsening of behavioral problems. The main purpose of parenting programs is to develop parents' ability to observe, 
Table 1. Search strategies

\begin{tabular}{|c|c|c|}
\hline $\begin{array}{l}\text { Search } \\
\text { engines }\end{array}$ & Prevalence of mental health problems among children & Evaluation of population-based parenting interventions \\
\hline PubMed & $\begin{array}{l}\text { "mental"[All Fields] AND "health"[All Fields] AND problem[All Fields] } \\
\text { AND "child"[All Fields] AND ("epidemiology"[All Fields] OR } \\
\text { "prevalence"[All Fields]) }\end{array}$ & $\begin{array}{l}\text { (“prevention”[All Fields]) AND (“parenting”[All Fields]) } \\
\text { AND (“population”[All Fields]) }\end{array}$ \\
\hline ProQuest & $\begin{array}{l}\text { ((SU.exact(“MENTAL HEALTH”)) AND SU.exact(“EPIDEMIOLOGY”)) } \\
\text { AND child }\end{array}$ & $\begin{array}{l}\text { ((SU.exact(“PARENTS”) OR SU.exact(“PARENTING”)) } \\
\text { AND SU.exact(“COMMUNITY”)) }\end{array}$ \\
\hline $\begin{array}{l}\text { CINAHL } \\
\text { with Full Text }\end{array}$ & mental health AND children AND prevalence AND survey & parenting AND prevention AND community \\
\hline $\begin{array}{l}\text { MEDLINE } \\
\text { with Full Text }\end{array}$ & mental health AND children AND prevalence AND survey & parenting AND prevention AND community \\
\hline
\end{tabular}

identify, and respond to their children's behaviors in new, more effective ways.

Parent-training programs have been developed as one component of comprehensive prevention and intervention methods for families of children with behavioral problems. ${ }^{8}$ Clinical trials have suggested that parent training improves parents' child-management skills and reduces children's misbehavior. ${ }^{9-18}$ In addition, parenting interventions lead to increased parent confidence, reduced stress, and improved family relationships. ${ }^{17}$

Parenting programs have great potential to improve children's quality of life, mental health, and family relationships, and to benefit the general public. However, traditional clinical models of service delivery cover a relatively small number of parents. A public-health approach is necessary to reach a larger number of parents and to have a societal-level impact. ${ }^{15}$ While clinic-based parent-training trials have been shown to be effective for families who visit the clinic, the proportion of parents who are not referred and have a need for these services is not known. To avoid biases that result from clinic-based studies, obtain a more representative community sample, and estimate the percentage of high-risk families who need parent training, a community approach that screens all kindergartens and/or schools in the community and identifies children who have behavioral problems is needed.

In order to develop effective prevention approaches for children's mental health problems in community settings, it is essential that good estimates of the prevalence of such problems are available in order to plan and deliver appropriate services. ${ }^{5,19}$ Although children's mental health problems tend to cluster among children from low-socio-economic-status families, a sizable number of cases arise from middle-class families, as these comprise a greater proportion of the population. ${ }^{5}$ Therefore, middle-class families are major contributors to the prevalence of emotional and behavioral problems.

In Japan, little is known about the prevalence of mental health problems; consequently, which kind of interventions should be put in place remains unclear. Information is needed about how nationwide prevalence data are summarized in other countries, what kinds of measures are taken to prevent mental health problems, and whether such measures are effective or not.

Therefore, to clarify the methods that may enable implementation of an effective approach in Japan to improve child mental health at the community level, we conducted a literature review to evaluate worldwide experiences of assessing prevalence of mental health problems among children and population interventions that aimed to lower the prevalence of these problems.

Although there are already a number of review studies about prevalence rates of mental health problems among children, ${ }^{20,21}$ we conducted the present review so that the results could be used as baseline data for developing new interventions. While review studies of randomized controlled trials of family behavior interventions have also been reported, ${ }^{22,23}$ we focused on intervention at the population level.

\section{METHODS}

Search engines and formulae used to identify relevant literature are shown in Table 1. Search results and evaluation of the identified studies are shown in Figure. We searched PubMed (a search engine provided by the United States National Library of Medicine), ProQuest (a crosssectional search among the ProQuest Public Health, ERIC, PILOTS, Social Service Abstract, and Sociological Abstract databases), CINAHL with Full Text (a full-text database covering 17 fields concerning nursing science), and MEDLINE with Full Text (a comprehensive full-text database of medical journals) for literature published after 1980. Separate searches were conducted for prevalence data and intervention effectiveness data.

We reviewed article titles and deleted papers dealing with issues obviously different from the aims of our study. We then evaluated abstracts and identified 36 papers that dealt with prevalence of mental health problems among children using national surveys or an equivalently wide area. Through full-text evaluation, we identified 12 papers in which the 

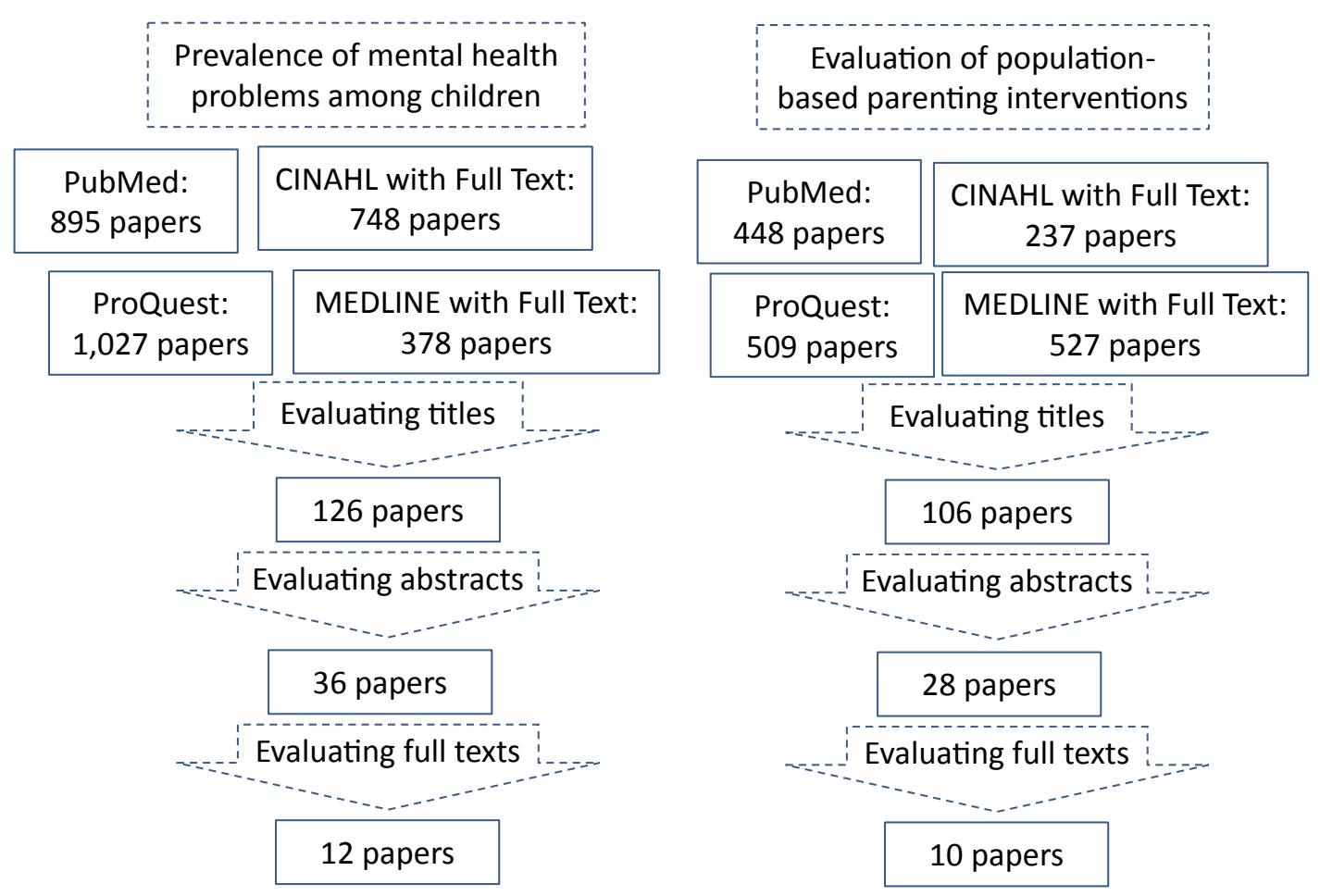

Figure. Search results and evaluation.

prevalence of mental health problems was assessed by either the Strength and Difficulty Questionnaire (SDQ) ${ }^{24}$ or Child Behavior Checklist (CBCL). ${ }^{25}$

For evaluation of population-based parenting interventions, we identified 28 papers through abstract analysis that dealt with evaluation of interventions at a population level. Through full-text evaluation, we identified 10 papers in which the target of the intervention was child behavioral problems and the results of evaluation were reported (not the study profile). In addition to these, we conducted extra searches through PubMed for Japanese literature dealing with prevalence of behavioral problems using nationally representative data, through which we found one Japanese study. We then examined the contents of the papers to summarize the information according to the aims of our study.

\section{RESULTS AND DISCUSSION}

\section{Prevalence of child mental health problems}

Table 2 shows the methods and results of regional or national mental health surveys among children. ${ }^{6,26-37}$ In all of the included surveys, sampling was carefully done to confirm representativeness and ensure that these studies would be informative for governments planning to conduct such surveys in the future. In addition to the SDQ and CBCL, various other evaluation scales were used, such as the Center for Epidemiological Studies Depression Scale for Children, ${ }^{38}$ the Screen for Child Anxiety Related Disorders, ${ }^{39}$ and the Symptom Checklist for Attention Deficit Hyperactivity Disorders. ${ }^{40,41}$
Among these studies, the proportions of children with clinically meaningful total difficulty according to the CBCL ranged from $10 \%$ to $20 \%$, and the sum of internalizing and externalizing disorders was similar. The corresponding proportions of children with clinically meaningful total difficulty according to the SDQ also ranged from $10 \%$ to $20 \%$. Behavioral problems are likely to lead to secondary mental health problems, such as depression, so managing the behavioral problems of children should be a policy priority. Only a minority (approximately 25\%) of children with behavioral problems were referred to medical services in the examined studies, suggesting that the majority of children are left untreated.

These results suggest that community interventions should focus not only on high-risk populations, as is often suggested in the literature, but also on implementation as early as possible.

\section{Evaluation studies of population parenting interventions}

Population-level interventions are potentially more effective than individual or selected approaches. ${ }^{15}$ Table 3 shows evaluation studies of population-level family interventions. Evaluation focused not only on behavioral problems of children but also on parental sense of confidence and parental stress or depression.

The majority of these studies ${ }^{8,17,42-49}$ recruited intervention samples using population-based sampling strategies to recruit high-risk children, implemented parenting programs, and evaluated the effectiveness among samples through pre- and 


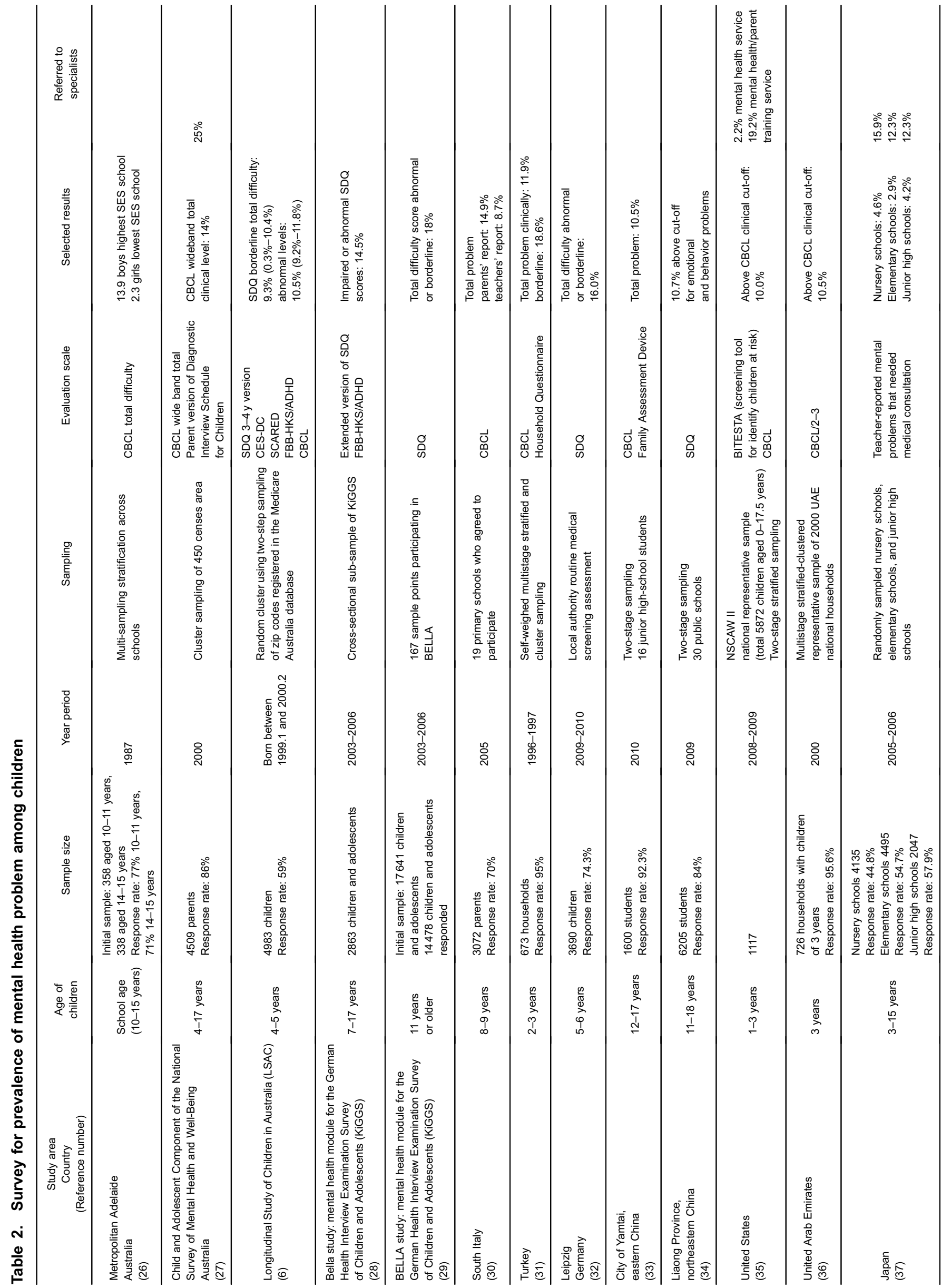




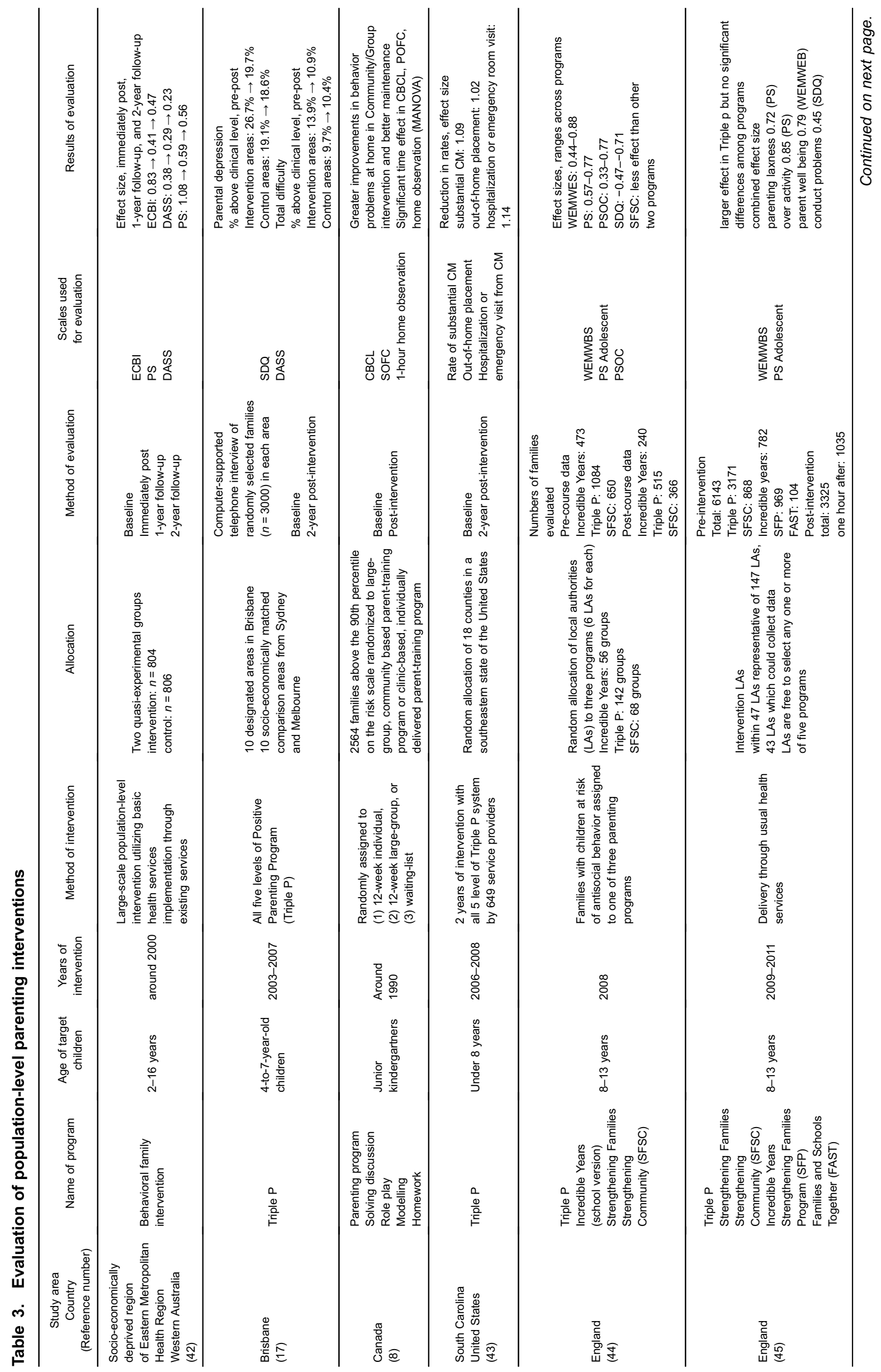




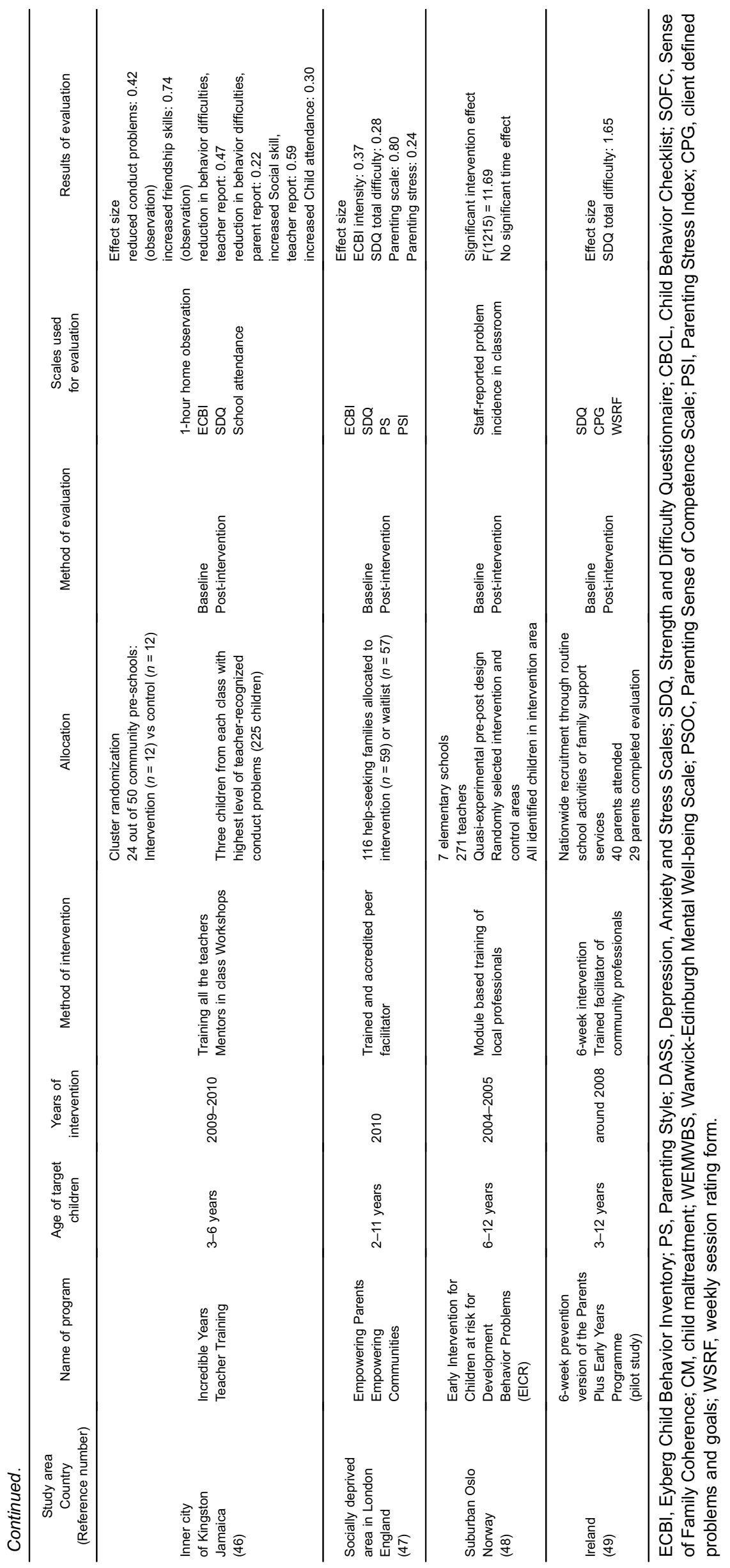


Table 4. Parenting programs implemented using a population approach

\begin{tabular}{|c|c|c|c|c|c|}
\hline Name of program & Theoretical basis & Characteristics & Target & Developer & Dissemination \\
\hline Triple P & $\begin{array}{l}\text { Child development } \\
\text { Therapeutic practice } \\
\text { Social learning }\end{array}$ & $\begin{array}{l}\text { Five levels suitable for each } \\
\text { level of problem }\end{array}$ & $\begin{array}{l}\text { Every parent of children } \\
\text { under } 16 \text { years }\end{array}$ & $\begin{array}{l}\text { Matthew R. Sanders } \\
\text { University of Queensland } \\
\text { Australia }\end{array}$ & 25 countries \\
\hline $\begin{array}{l}\text { Strengthening Families } \\
\text { Strengthening Communities } \\
\text { (SFSC) }\end{array}$ & $\begin{array}{l}\text { Family stress } \\
\text { Children's development } \\
\text { Social learning Ecological }\end{array}$ & Culturally sensitive program & $\begin{array}{l}\text { Any families including ethnic } \\
\text { minority children }\end{array}$ & $\begin{array}{l}\text { Race Equity Foundation } \\
\text { United Kingdom } \\
\text { (formerly developed in United States) }\end{array}$ & $\begin{array}{l}\text { United Kingdom } \\
\text { United States }\end{array}$ \\
\hline Incredible Years & $\begin{array}{l}\text { Social learning } \\
\text { Self-efficacy } \\
\text { Cognitive behavioral } \\
\text { Piaget's developmental }\end{array}$ & $\begin{array}{l}\text { Parent version } \\
\text { Child version } \\
\text { Teacher version }\end{array}$ & Children at risk & $\begin{array}{l}\text { Carolyn Webster-Stratton } \\
\text { University of Washington } \\
\text { United States }\end{array}$ & 26 countries \\
\hline $\begin{array}{l}\text { Strengthening Families } \\
\text { Program } \\
\text { (SFP) }\end{array}$ & $\begin{array}{l}\text { Biosychosocial } \\
\text { Vulnerability } \\
\text { Resiliency } \\
\text { Family process }\end{array}$ & $\begin{array}{l}\text { Optional interventions } \\
\text { according to level of risks } \\
\text { and age of children }\end{array}$ & $\begin{array}{l}\text { Caregivers of any children } \\
\text { aged } 6-17\end{array}$ & $\begin{array}{l}\text { Karol Kumpfer } \\
\text { Office of drug control } \\
\text { University of lowa } \\
\text { United States }\end{array}$ & 26 countries \\
\hline
\end{tabular}

post-intervention assessments. Among such studies, only half also included control groups for comparison.

Two studies used variant types of study design, in which the intervention was provided at various levels of intensity, and families received the relevant intensity of intervention based on the degree of behavioral issues. ${ }^{17,43}$ Through such an approach, almost all families in the study area receive some kind of intervention. One of the two studies evaluated the effect using a questionnaire sent to randomly sampled families within the region. ${ }^{17}$ The other study measured the occurrence of child maltreatment before and after 2 years of intervention, which corresponds to a long-term effect. ${ }^{43}$ Although the assessed outcome was not child behavior or family wellbeing, child maltreatment tends to occur through severe impairment of such indicators. In reports from Jamaica ${ }^{46}$ and Norway, ${ }^{48}$ the intervention was conducted by teachers, which is a variant type of parenting intervention.

Although most of these studies summarize the results using effect sizes, they also report decreases in the percentages of children with assessment scores above the clinical level. Improving the outcomes for high-risk children can lead to considerable reductions in the proportions of children with problems at the population level of each scale. Some studies ${ }^{44,45}$ implemented different programs among communities, with the effectiveness compared among programs. Each program had some degree of prevalence change in each setting.

Through our review, we found that researchers are still seeking better methods for community intervention and evaluation. The most important goal of a given method is to deliver programs to all families in the community who need support. ${ }^{15}$

Table 4 provides a comparison among manualized parenting programs (ie, those with manuals, textbooks, or other published materials $)^{50-53}$ that were implemented and evaluated through a population approach. ${ }^{17,43-46}$ Almost all of the programs were based on scientific theories, were disseminated among many countries, and introduced a universal approach targeting all families in a community. Each program also had unique characteristics that distinguished it from the others. The Positive Parenting Program (Triple $\mathrm{P})^{50}$ provides a multilevel approach according to the severity of the problem. Optional interventions were provided according to risk level in Strategic Prevention Framework programs. ${ }^{53}$ Incredible Years ${ }^{52}$ provided not only parent versions but also child and teacher versions. One of the programs ${ }^{51}$ was culturally sensitive and designed for disadvantaged families. The variety of available programs allows policymakers to choose the program that is suitable for the problems of their own communities.

Systematic screening of preschoolers or schoolchildren may identify issues that can be considered precursors to later problems, which suggests that universal screening may be beneficial. $^{7}$ An approach that utilizes a universal service system that is accessed by all or nearly all children and an acceptable screening tool for the systematic identification of at-risk children are needed.

Population exposure to interventions may result in a significant reduction of the total number of behavioral problems, even though reductions at the individual level may be modest. ${ }^{17}$ Children with mild behavioral problems make up a large part of the community population, and their improvement could be of substantial benefit to the community. ${ }^{17}$

\section{Future perspectives}

We reviewed the prevalence of mental health problems among children in the community and the effect of universal family intervention at the population level, which may reduce the prevalence of children's mental health problems. The reviewed evidence shows that children's and families' mental health improved on a variety of measures as a result of community intervention. In particular, a decrease in the prevalence of child maltreatment was reported through the community approach. 
If we were to choose the kind of intervention method likely to the have greatest benefit for the population, it would be a comprehensive intervention, such as Triple $\mathrm{P}$, which targets not only severe cases but also apparently normal children showing precursors to later problems. In Japan, construction of a surveillance system of mental health problems among children would be helpful to guide policymaking for community interventions and to evaluate the effectiveness of such interventions.

One of the most important aims of community intervention is to modify mild behavioral problems to prevent the future development of more serious mental problems. Therefore, large-scale, long-term follow-up studies will be needed to evaluate the effect of these preventive measures.

\section{Limitations and conclusions}

There are some limitations in the present study. First, the issues identified in the present study are not covered by only medical or health science. Our approach was limited to health and medical databases, but a more extensive search through social, psychological, and cultural databases may identify other relevant research. However, sufficient evidence was obtained from the databases to which we had access to obtain a general overview of key issues. Second, there is publication bias in the literature, as negative results are not likely to be published. To minimize publication bias, better search methods or methods of analysis are needed to identify positive and negative results. Despite these limitations, the information presented here could be useful for political decision-making regarding the conduct of mental health surveys among children and the delivery of adequate community-based interventions.

In conclusion, we clarified through a literature review that mental health problems among children are common across countries and require political commitment to address issues at a population level. We identified several promising community-level family interventions that may be effective in addressing such problems.

\section{ONLINE ONLY MATERIAL}

Abstract in Japanese.

\section{ACKNOWLEDGMENTS}

The Triple P-Positive Parenting Program is owned by the University of Queensland (UQ). The University (through its main technology transfer company, UniQuest Pty Ltd.) has licensed Triple $\mathrm{P}$ International Pty Ltd. to publish and disseminate the program worldwide. Royalties stemming from published Triple $P$ resources are distributed to the Faculty of Health and Behavioural Sciences at UQ, Parenting and Family Support Centre, School of Psychology at UQ, and contributory authors. AM does not have any share or ownership in Triple P International Pty Ltd. AM is an author on various Triple $\mathrm{P}$ resources.

Conflicts of interest: None declared.

\section{REFERENCES}

1. Patel V, Flisher AJ, Hetrick S, McGorry P. Mental health of young people: a global public-health challenge. Lancet. 2007; 369:1302-13.

2. Palfrey JS, Tonniges TF, Green M, Richmond J. Introduction: Addressing the millennial morbidity - the context of community pediatrics. Pediatrics. 2005;115:1121-3.

3. Belfer ML. Child and adolescent mental disorders: the magnitude of the problem across the globe. J Child Psychol Psychiatry. 2008;49:226-36.

4. Biederman J, Rosenbaum JF, Bolduc-Murphy EA, Faraone SV, Chaloff J, Hirshfeld DR, et al. A 3-year follow-up of children with and without behavioral inhibition. J Am Acad Child Adolesc Psychiatry. 1993;32:814-21.

5. Bayer JK, Hiscock H, Ukoumunne OC, Price A, Wake M. Early childhood aetiology of mental health problems: a longitudinal population-based study. J Child Psychol Psychiatry. 2008;49: 1166-74.

6. Davis E, Sawyer MG, Lo SK, Priest N, Wake M. Socioeconomic risk factors for mental health problems in 4-5-year-old children: Australian population study. Acad Pediatr. 2010;10:41-7.

7. Bayer JK, Rapee RM, Hiscock H, Ukoumunne OC, Mihalopoulos C, Clifford S, et al. The Cool Little Kids randomised controlled trial: population-level early prevention for anxiety disorders. BMC Public Health. 2011;11:11.

8. Cunningham CE, Bremner R, Boyle M. Large group community-based parenting programs for families of preschoolers at risk for disruptive behaviour disorders: utilization, cost effectiveness, and outcome. J Child Psychol Psychiatry. 1995;36:1141-59.

9. Fergusson DM, Grant H, Horwood LJ, Ridder EM. Randomized trial of the Early Start program of home visitation. Pediatrics. 2005;116:e803-9.

10. Fergusson DM, Grant H, Horwood LJ, Ridder EM. Randomized trial of the Early Start program of home visitation: parent and family outcomes. Pediatrics. 2006;117:781-6.

11. Kennedy SJ, Rapee RM, Edwards SL. A selective intervention program for inhibited preschool-aged children of parents with an anxiety disorder: effects on current anxiety disorders and temperament. J Am Acad Child Adolesc Psychiatry. 2009;48: 602-9.

12. Rapee RM, Kennedy S, Ingram M, Edwards S, Sweeney L. Prevention and early intervention of anxiety disorders in inhibited preschool children. J Consult Clin Psychol. 2005;73: 488-97.

13. Roberts C, Mazzucchelli T, Studman L, Sanders MR. Behavioral family intervention for children with developmental disabilities and behavioral problems. J Clin Child Adolesc Psychol. 2006; 35:180-93.

14. Fujiwara T, Kato N, Sanders MR. Effectiveness of Group Positive Parenting Program (Triple P) in changing child behavior, parenting style, and parental adjustment: An intervention study in Japan. J Child Fam Stud. 2011;20:804-14. 
15. Sanders MR. Triple P-Positive Parenting Program as a public health approach to strengthening parenting. J Fam Psychol. 2008;22:506-17.

16. Sanders MR, Bor W, Morawska A. Maintenance of treatment gains: a comparison of enhanced, standard, and self-directed Triple P-Positive Parenting Program. J Abnorm Child Psychol. 2007;35:983-98.

17. Sanders MR, Ralph A, Sofronoff K, Gardiner P, Thompson R, Dwyer S, et al. Every family: a population approach to reducing behavioral and emotional problems in children making the transition to school. J Prim Prev. 2008;29:197-222.

18. Turner KM, Sanders MR. Help when it's needed first: a controlled evaluation of brief, preventive behavioral family intervention in a primary care setting. Behav Ther. 2006;37: 131-42.

19. Roberts RE, Attkisson CC, Rosenblatt A. Prevalence of psychopathology among children and adolescents. Am J Psychiatry. 1998;155:715-25.

20. Costello EJ, Egger H, Angold A. 10-year research update review: the epidemiology of child and adolescent psychiatric disorders: I. Methods and public health burden. J Am Acad Child Adolesc Psychiatry. 2005;44:972-86.

21. Kessler RC, Amminger GP, Aguilar-Gaxiola S, Alonso J, Lee S, Ustun TB. Age of onset of mental disorders: a review of recent literature. Curr Opin Psychiatry. 2007;20:359-64.

22. Durlak JA, Wells AM. Primary prevention mental health programs for children and adolescents: a meta-analytic review. Am J Community Psychol. 1997;25:115-52.

23. Bayer J, Hiscock H, Scalzo K, Mathers M, McDonald M, Morris A, et al. Systematic review of preventive interventions for children's mental health: what would work in Australian contexts? Aust N Z J Psychiatry. 2009;43:695-710.

24. Goodman R. The Strengths and Difficulties Questionnaire: a research note. J Child Psychol Psychiatry. 1997;38:581-6.

25. Achenbach T. Manual for the Child Behavior Checklist/4-18. Burlington: University of Vermont; 1991.

26. Sawyer MG, Sarris A, Baghurst PA, Cornish CA, Kalucy RS. The prevalence of emotional and behaviour disorders and patterns of service utilisation in children and adolescents. Aust N Z J Psychiatry. 1990;24:323-30.

27. Sawyer MG, Arney FM, Baghurst PA, Clark JJ, Graetz BW, Kosky RJ, et al. The mental health of young people in Australia: key findings from the child and adolescent component of the national survey of mental health and well-being. Aust $\mathrm{N} \mathrm{Z} \mathrm{J}$ Psychiatry. 2001;35:806-14.

28. Ravens-Sieberer U, Wille N, Erhart M, Bettge S, Wittchen HU, Rothenberger A, et al. Prevalence of mental health problems among children and adolescents in Germany: results of the BELLA study within the National Health Interview and Examination Survey. Eur Child Adolesc Psychiatry. 2008;17 Suppl 1:22-33.

29. Holling H, Kurth BM, Rothenberger A, Becker A, Schlack R. Assessing psychopathological problems of children and adolescents from 3 to 17 years in a nationwide representative sample: results of the German health interview and examination survey for children and adolescents (KiGGS). Eur Child Adolesc Psychiatry. 2008;17 Suppl 1:34-41.

30. Gritti A, Bravaccio C, Signoriello S, Salerno F, Pisano S, Catone
G, et al. Epidemiological study on behavioural and emotional problems in developmental age: prevalence in a sample of Italian children, based on parent and teacher reports. Ital J Pediatr. 2014;40:19.

31. Erol N, Simsek Z, Oner O, Munir K. Behavioral and emotional problems among Turkish children at ages 2 to 3 years. J Am Acad Child Adolesc Psychiatry. 2005;44:80-7.

32. Fuchs S, Klein AM, Otto Y, von Klitzing K. Prevalence of emotional and behavioral symptoms and their impact on daily life activities in a community sample of 3 to 5 -year-old children. Child Psychiatry Hum Dev. 2013;44:493-503.

33. Ma X, Yao Y, Zhao X. Prevalence of behavioral problems and related family functioning among middle school students in an eastern city of China. Asia Pac Psychiatry. 2013;5:E1-8.

34. Wang JN, Liu L, Wang L. Prevalence and associated factors of emotional and behavioural problems in Chinese school adolescents: a cross-sectional survey. Child Care Health Dev. 2014;40:319-26.

35. McCue Horwitz S, Hurlburt MS, Heneghan A, Zhang J, RollsReutz J, Fisher E, et al. Mental health problems in young children investigated by U.S. child welfare agencies. J Am Acad Child Adolesc Psychiatry. 2012;51:572-81.

36. Eapen V, Yunis F, Zoubeidi T, Sabri S. Problem behaviors in 3-year-old children in the United Arab Emirates. J Pediatr Health Care. 2004;18:186-91.

37. Izumi M, Okuyama M. A survey of children with mental health problems in Japanese nursery, elementary and journior high school. J Japan Pediatr Soc. 2008;112:476-82.

38. Faulstich ME, Carey MP, Ruggiero L, Enyart P, Gresham F. Assessment of depression in childhood and adolescence: an evaluation of the Center for Epidemiological Studies Depression Scale for Children (CES-DC). Am J Psychiatry. 1986;143: 1024-7.

39. Birmaher B, Brent DA, Chiappetta L, Bridge J, Monga S, Baugher M. Psychometric properties of the Screen for Child Anxiety Related Emotional Disorders (SCARED): a replication study. J Am Acad Child Adolesc Psychiatry. 1999;38:1230-6.

40. Conners CK. Issues in the study of adolescent ADD-H/ hyperactivity. Psychopharmacol Bull. 1985;21:243-50.

41. Kessler RC, Ustun TB. The World Mental Health (WMH) Survey Initiative Version of the World Health Organization (WHO) Composite International Diagnostic Interview (CIDI). Int J Methods Psychiatr Res. 2004;13:93-121.

42. Zubrick SR, Ward KA, Silburn SR, Lawrence D, Williams AA, Blair E, et al. Prevention of child behavioral problems through universal implementation of a group behavioral family intervention. Prev Sci. 2005;6:287-304.

43. Prinz RJ, Sanders MR, Shapiro CJ, Whitaker DJ, Lutzker JR. Population-based prevention of child maltreatment: the U.S. Triple p system population trial. Prev Sci. 2009;10:1-12.

44. Lindsay G, Strand S, Davis H. A comparison of the effectiveness of three parenting programmes in improving parenting skills, parent mental-well being and children's behaviour when implemented on a large scale in community settings in 18 English local authorities: the parenting early intervention pathfinder (PEIP). BMC Public Health. 2011;11:962.

45. Lindsay G, Strand S. Evaluation of the national roll-out of parenting programmes across England: the parenting early 
intervention programme (PEIP). BMC Public Health. 2013;13: 972.

46. Baker-Henningham H, Scott S, Jones K, Walker S. Reducing child conduct problems and promoting social skills in a middleincome country: cluster randomised controlled trial. $\mathrm{Br} \mathrm{J}$ Psychiatry. 2012;201:101-8.

47. Day C, Michelson D, Thomson S, Penney C, Draper L. Evaluation of a peer led parenting intervention for disruptive behaviour problems in children: community based randomised controlled trial. BMJ. 2012;344:e1107.

48. Kilroy S, Sharry J, Flood C, Guerin S. Parenting training in the community: linking process to outcome. Clin Child Psychol Psychiatry. 2011;16:459-73.

49. Kjobli J, Sorlie MA. School outcomes of a community-wide intervention model aimed at preventing problem behavior. Scand J Psychol. 2008;49:365-75.

50. Sanders MR. Triple P-Positive Parenting Program: towards an empirically validated multilevel parenting and family support strategy for the prevention of behavior and emotional problems in children. Clin Child Fam Psychol Rev. 1999;2:71-90.

51. Matthew RF, Wang MQ, Bellamy N, Copeland E. Test of Efficacy of Model Family Strengthening Programs. Am J Health Studies. 2005;20:164-70.

52. Webster-Stratton C, Reid MJ, Hammond M. Treating children with early-onset conduct problems: intervention outcomes for parent, child, and teacher training. J Clin Child Adolesc Psychol. 2004;33:105-24.

53. Coatsworth JD, Duncan LG, Berrena E, Bamberger KT, Loeschinger D, Greenberg MT, et al. The Mindfulnessenhanced Strengthening Families Program: integrating brief mindfulness activities and parent training within an evidencebased prevention program. New Dir Youth Dev. 2014;2014: $45-58$. 